\title{
Uterin Arter Embolizasyonu Sonrası Myoma Uterinin Ekspulsiyonu: Olgu sunumu
}

Expulsion of a Uterine Myoma After Uterine Artery Embolization: Case Report

\author{
Ali Cenk ÖZAY ${ }^{1}$, Özlen EMEKÇİ ${ }^{1}$, Berrin ACAR ${ }^{1}$, Aygün AKBEROVA ${ }^{1}$, Aslı AKDÖNER ${ }^{1}$ \\ 1. Dokuz Eylül Üniversitesi Kadın Hastalıkları ve Doğum Anabilimdalı, İmir, Türkiye
}

\section{$\ddot{O Z E T}$}

Giriş: Uterin arter embolizasyonundan sonra myomların servikal prolapsusu nadir görülen $d u$ rumlardan biridir. Kavite içerisindeki saplı, büyük çaplı, küçüldügünde prolabe olabilecek myomlarda dikkatli olunması gereklidir.

Olgu: Anormal vajinal kanama ile başvuran 42 yaşındaki hastanın yapılan jinekolojik değerlendirmesinde $10 \times 11 \mathrm{~cm}$ myom saptand . Cerrahi tedaviyi kabul etmeyen hastaya uterin arter embolizasyonu uyguland $\mathrm{I}$. Islemden 8 gün sonra myom prolapsusu ve yoğun vajinal kanama ile acil servise başvuran hastaya total abdominal histerektomi yapild.

Sonuç: Büyük çapll myomlar uterin arter embolizasyonundan her zaman fayda görmemektedir.

Anahtar Kelimeler: myom; embolizasyon; ekspulsiyon

\section{ABSTRACT}

Introduction: Cervical prolapse of fibroids is one of the rare condition after uterine artery embolization.

Case Report: A 42 years old woman was admitted with abnormal vaginal bleeding. In her vaginal examination $6 \mathrm{~cm}$ myoma was detected. She refused operation and therefore uterine artery was embolization was done. 8 days after the embolization she was admitted to emergency unit with prolapse of the myoma and vaginal bleeding and she had total abdominal hysterectomy.

Conclusion: Large myomas won't always benefit from uterin artery embolization.

Keywords: myoma; embolization; expulsion

\footnotetext{
İletişim:

Sorumlu Yazar: Ali Cenk ÖZAY

Adres: Dokuz Eylül Ünv. Kadın Hast. ve Doğum Anabilimdalı, Mithatpaşa Cd:1606 İnciraltı Yer. 35340 Balçova, İzmir Tel: +90 (232) 4123130

E-Posta: dr.alicenk@hotmail.com

Makale Geliş: 15.01.2015

Makale Kabul: 24.11.2015

DOI: http://dx.doi.org/10.16948/zktipb.237119
}

\section{GíRiş}

Uterin arter embolizasyonu (UAE) 1970 yıllarından itibaren obstetrik ve jinekolojik kanamaların tedavisinde, 1995 y1lından beri myoma uterinin tedavisinde kullanılmaktadır. Çalışmalar; UAE sonrası myomun çapının \%50 azaldı ğını ve hastaların \%80-90'ında şikayetlerin gerilediğini göstermiștir. Komplikasyonun az olduğu bildirilmiştir $(1,2)$. Bu komplikasyonlardan biri olan myom ekspulsiyonu \%3-5 oranında izlenmektedir ve bu durum birçok olguda embolizasyon sonrası yaklaşık 3. aya kadar görülmektedir $(3,4)$. Kavite içerisindeki saplı, büyük çaplı, küçüldüğünde prolabe olabilecek myomlarda dikkatli olunması gereklidir.

\section{OLGU SUNUMU}

Menometroraji şikayetiyle başvuran ve bu şikayetinin sekiz aydır devam ettiğini belirten 42 yaşında gravida 2, parite 2 olan hasta ek olarak karnında şişlik olduğunu belirtmekteydi. Hastanın jinekolojik muayenesinde uterus 16 haftalık gebelik cesametinde saptand1. Jinekolojik ultrasonda (USG) uterus korpus posteriorda yaklaşık $10 \mathrm{~cm}$ X $11 \mathrm{~cm}$ çapında intramural kaviteye uzanan myom nüvesi izlendi. Myom MR görüntülemesinde uterus korpus superiorda intramural yerleşimli hetorojen nitelikte $12 \times 11 \times 9 \mathrm{~cm}$ boyutlarında (Resim 1), endometrial kaviteyi inferiora deplase etmiş görünümdeydi. Ciddi menoraji nedeni ile hastanın hemoglobin düzeyi $7,1 \mathrm{~g} / \mathrm{dL}$, hematokrit değeri \%21 saptand1. PT, aptt, kanama zamanı, platelet sayısı normal seviyedeydi.

Daha önce aldiğ 1 medikal tedavilerden fayda görmeyen hastaya myomektomi önerildi. Hastanın cerrahi herhangi bir tedaviyi istemediğini belirtmesi üzerine hastaya alternatif tedavi seçenekleri anlatıldı. Sonrasında hastaya UAE uyguland1. Hasta işlemden 8 gün sonra vajende ele gelen kitle, şiddetli ağrı ve vajinal kanama yakınması ile hastaneye başvurdu.

Spekulum muayenesinde vajeni dolduran $6 \times 5 \mathrm{~cm}$ çaplı kitle ve yoğun vajinal kanama izlendi. Elle muayene ile myom nuvesinin servikal kanala uzandığ 
Hastanın bakılan hemoglobin düzeyi 6,7 g/ $\mathrm{dL}$ ve hematokrit değeri \%19,1 olması üzerine hastaya 3 ünite eritrosit süspansiyonu verildi.

Hasta acil olarak operasyona alınd1. Hastanın hemodinamik açıdan stabil olmaması, yoğun kanamasının olması ve myomektomi s1rasında olabilecek kanama miktarının hastanın durumunu daha kötüye götürebileceği gözönünde bulundurularak total abdominal histerektomi kararı alındı. Postoperatif olarak patoloji materyalinde, nekroze görünümde ve serviksten dișarı uzanım gösteren myom izlendi (Re$\operatorname{sim} 2)$.

Postoperatif 3. günde hasta klinik, laboratuar ve vital bulgularında anormallik olmamas1 üzerine taburcu edildi. Patolojik incelemede myoma uteri tanısı doğruland1. Mikroskopik olarak akut ve kronik endometrit, nekrotik leyomyom tespit edildi. UAE bağlı intravaskular trombozlar izlendi.

\section{TARTIŞMA}

Uterin arter embolizasyonu durdurulamayan post-operatif kanamalar için uzun süredir kullanılmaktadır ve 1990'larda myomda da tedavi yöntemi olarak kullanılmaya başlanmıştır. UAE ile uterus ve myom boyutlarında \%40-50 azalma, ağrı ve kanamada \%80 azalma bildirilmiştir $(5,6)$. İskemi ve nekroz nedeniyle şiddetli ağriya neden olabilmesi, enfeksiyon ve sepsis riskinin bulunması, radyasyona bağlı prematür menopoz, infertiliteye neden olabilmesi, leomyosarkom tanısında gecikme gibi dezavantajları vardır (7). McLucas ve arkadaşları myom nedeniyle cerrahi öyküsü olan hastalarda UAE tedavisinin başarısının azaldığını, myom ve uterusun boyutunun ise tedavi başarısını etkilemediğini belirtmişlerdir (8). Buna karşın Goodwin ve arkadaşları eşik değer belirtmemekle birlikte artmış myom boyutu ve sayısının UAE tedavisinin başarısını olumsuz etkilediğini bildirmişlerdir (9).

Uterin arter embolizasyonu sonrası myom ekspulsiyonu haftalar veya yıllar içerisinde olabilmektedir $(10,11)$. UAE sonras1 nekroza uğrayan myom dokusu zamanla myometrium tarafından çevrelenerek absorbe edilir yada uterustan atılır (4). Myomun, UAE sonrası transservikal ekspulsiyonu nadiren görülen durumlardan biridir (11). Shlansky-Goldberg ve arkadaşlarının çalıșmasında retrospektif olarak incelenen 759 UAE uygulanmış hastanın 37'sinde myom ekspulsiyonu saptanmış ve myom ekspulsiyonunun UAE sonrasi ortalama 14.8 hafta sonrasında olduğu belirtilmiştir (12). Bizim olgumuzda ekspulsiyon UAE sonrası sekizinci günde aşırı vajinal kanama ve ağrı ile gerçekleşmiştir.

Myomektomi UAE sonrası tercih edilebilecek bir tedavi yöntemidir. Ancak bizim olgumuzda kanamanın yoğunluğu, myomektomi sirasinda olabilecek kanama ile hastanın hemodinamik durumu, hemoglobin değerleri
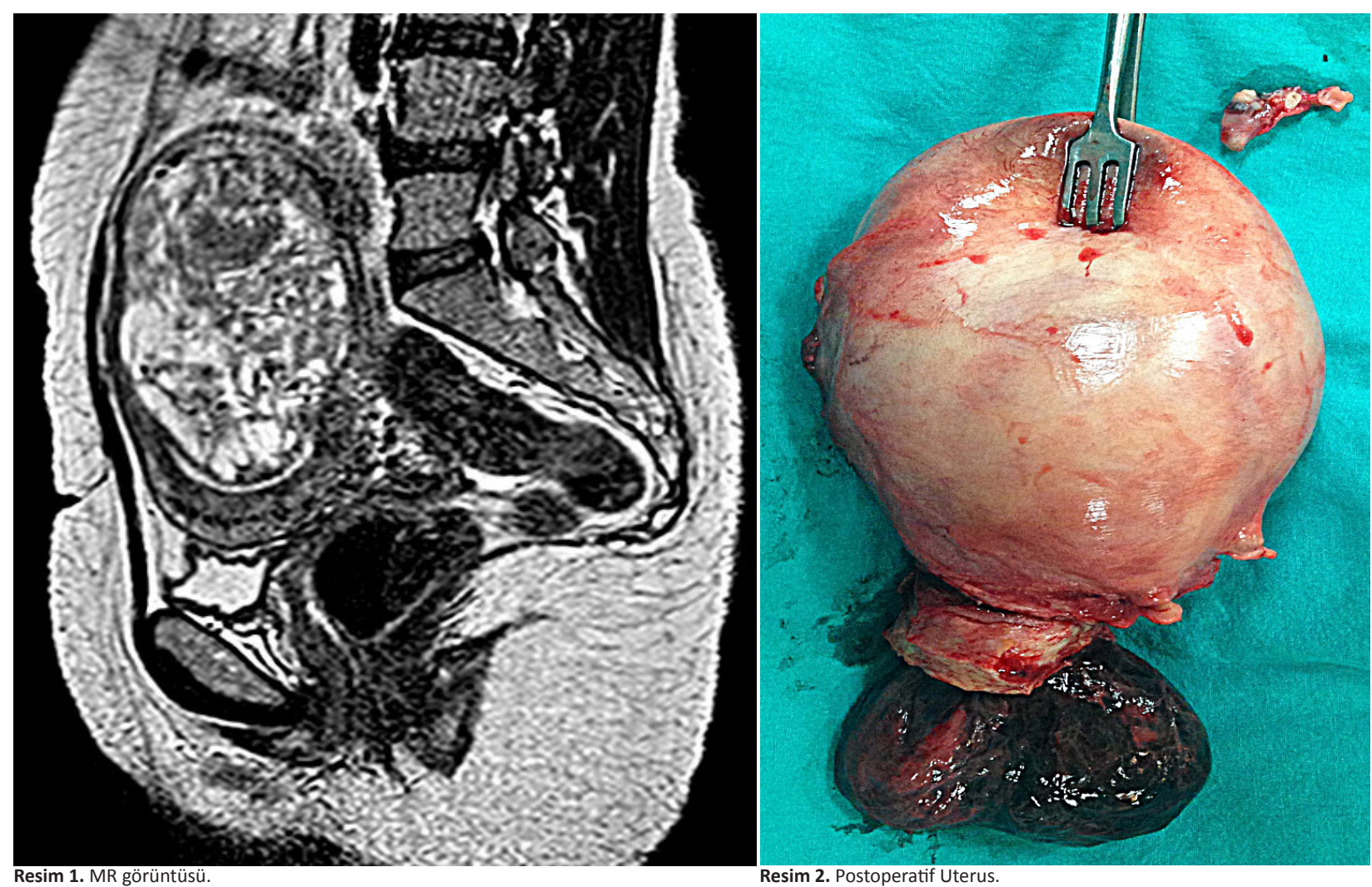
gözönünde bulundurularak ve hastanın onamı alınarak histerektomi tercih edilmiștir. İntrakaviter büyük çaplı myomların embolizasyon sonrasında boyutları küçülünce, prolabe olabileceği ve ciddi kanamalara neden olabileceği gözönünde bulundurulmalıdır. Bu konuda literatürde yeterli veri yoktur ve vaka serilerine ihtiyaç vardır.

Uterin arter embolizasyonu sonrası myom ekspulsiyonu, myomun tüm olarak veya iri parçalar halinde ekspulsiyonu şeklinde olabileceği gibi, myomun zaman içinde endometrial doku ile eriyip çözünerek küçük parçalar halinde ekspulsiyonu şeklinde de olabilir (12). Bizim olgumuzda erime şeklinde ekspulsiyon söz konusudur.

Goodwin ve arkadaşları UAE sonrası histerektomi oranın $\% 9.8$, myomektomi oranın $\% 2.8$ ve tekrarlayan UAE oranın $\% 1.8$ olarak bildirmişlerdir (9).

UAE sonrası gelişen myom ekspulsiyonu olgularında, uygulanan cerrahi siklıkla myomektomi olmasına rağmen bizim olgumuzda hastanın kanamasinın fazla olması, hemodinamik instabilite ve myomektomi sirasinda olabilecek kanamanın, hastanın genel durumunu daha çok bozması gözönünde bulundurularak histerektomi uygulandi.

Sonuç olarak; UAE tedavisi olgumuzda da olduğu gibi bazen başarısızlıkla sonuçlanabilmektedir. Nadiren UAE tedavisi sonrası, myom boyutundaki küçülme ve myomun prolabe olması nedeniyle, böyle bir komplikasyon ile karşılaşılabileceği gözönünde bulundurulmal1dır. UAE tedavisinin başarısı myomun boyutu, yerleşimi, klinisyenin deneyimi gibi birçok faktöre bağlı olabilir. UAE sonrası myom ekspulsiyonunda hastanın kliniği gözönünde bulundurularak myomektomi veya histerektomi uygulanabilir.

\section{KAYNAKLAR}

1. Goodwin SC, McLucas B, Vdantham S, Perrella S. Preliminary experience with uterine artery embolization for uterine fibroids. J Vasc Interve Radiol. 1997 ;8:517-526.

2. Ravina JH, Herbreteau D, Ciraru-Vigneron N, Bouret JM, Houdart E, Aymard A, Merland JJ. Arterial embolisation to treat uterine myomata. Lancet. 1995 Sep 9;346(8976):671-2.

3. Marret H, Keris Yle B, Acker O, Cottier JP, Herbreteau $D$. Late leiomyoma expulsion after uterine artery embolization. J Vasc Interv Radiol 2004; 15:1483-1485.

4. Hehenkamp WJ, Volkers NA, Montauban Van Swijndregt AD, Blok SD, Reekers JA, Ankum WM. Myoma expulsion after uterine artery embolization: complication or cure? Am J Obstet Gynecol. 2004; 191:1713-1715.

5. Goodwin SC, McLucas B, Lee M. Uterine artery embolisation for treatment of uterine leiomyomata midterm results. J Vasc Interv Radiol. 1999;10:1159-65.

6. Siskin GP, Stainken BF, Dowling K. Outpatient uterine arteryembolisation for symptomatic uterine fibroids: experience in 49patients. J Vasc Inerv Radiol. 2000;11:305-11.

7. Olive DL. New approches to management of fibroids. Obstet Gynecol Clin North Am. 2000;27:669-77.

8. McLucas B, Adler L, Perrella R. Uterine fibroid embolization: nonsurgical treatment for symptomatic fibroids. $J$ Am Coll Surg. 2001a;192:95-105.

9. Goodwin SC, Spies JB, Worthington-Kirsch R, Peterson E, Pron G, Li S, Myers E. Uterine artery embolization for treatment of leiomyomata. Long-term outcomes from the FIBROID Registry. Obstet Gynecol. 2008;111:22-33.

10. Laverge F, D'Angelo A, Davies NJ, Wood A, Amso NN. Spontaneous expulsion of three large fibroids after uterine artery embolization. Fertil Steril 2003; 80:450-452.

11. Abbara S, Spies JB, Scialli AR, Jha RC, Lage JM, Nikolic B. Transcervical expulsion of a fibroid as a result of uterine artery embolization for leiomyomata, J Vasc Interv Radiol. 1999 Apr;10(4):409-11.

12. Shlansky-Goldberg RD, Coryell L, Stavropoulos SW, Trerotola SO et all. Outcomes Following Fibroid Expulsion after Uterine Artery Embolization. J Vasc Interv Radiol. 2011; 22:1586-1593. 